\author{
Cadernos de \\ ESTUdOS LINGüĺsTICOS - (56.2), Campinas, Jul./Dez. 2014
}

\title{
CATEGORIZAÇÃO E REFERÊNCIA: UMA ABORDAGEM DISCURSIVA
}

\author{
ALENA CIULLA \\ UFRGS
}

\begin{abstract}
RESUMO: Neste trabalho, nosso objetivo é refletir sobre o conceito de categorização, levando em consideração uma dimensão discursiva em que aspectos cognitivos e interacionais estão em jogo. A partir desse enfoque, revisitamos também algumas estratégias de (re)categorização anafórica sugeridas na literatura e demonstramos, a partir de exemplos, a estreita relação da categorização com o processo referencial: ao escolher uma expressão, entre todas as opções que julgar adequadas, o falante privilegia alguns aspectos em detrimento de outros, de acordo com as abstrações, generalizações e outros tipos de associações que a palavra escolhida pode suscitar, o que contribui de maneira crucial para a construção da referência. Além disso, confirmamos a noção de que os objetos do discurso são evolutivos, já que podem ser redefinidos a cada nova interação entre os falantes. Por fim, mostramos que o fenômeno da categorização não se restringe a operações meramente lexicais, mas se apóia na capacidade de inferência do interlocutor, no seu conhecimento de mundo e no conhecimento compartilhado entre os falantes.

Palavras-chave: categorização; referenciação; anáfora.
\end{abstract}

\begin{abstract}
In this work, the concept of categorization is discussed. It is taken into account a discursive dimension in which cognitive and interactional aspects are at stake. From this approach, some (re)categorization strategies suggested in the literature are also revisited. It is demonstrated, through examples, the close relationship between categorization and referential process: when choosing an expression out of all the options that he deems appropriate, the speaker emphasizes some aspects rather than others, according to the abstractions, generalizations and other types of associations that the word can raise, which is a crucial contribution to the construction of reference. Furthermore, the notion that the objects of discourse are evolutionary is confirmed, since the objects can be reset in every new interaction between speakers. Finally, it is demonstrated that the phenomenon of categorization cannot be restricted to purely lexical operations, since it relies rather on inference capability, knowledge of the world and knowledge shared between the speakers.
\end{abstract}

Keywords: categorization, reference process; anaphora.

\section{INTRODUÇÃO}

A categorização é um fenômeno intimamente ligado ao processo referencial, conforme demonstramos neste trabalho. Em Ciulla (2008), dissemos que, ao referir, os falantes "percebem" o mundo e, ao fazê-lo, também distinguem, classificam e designam as coisa a sua volta; esse procedimento cognitivo é chamado de categorização.

A perspectiva sobre referência que adotamos toma como base a posição de Mondada e Dubois [1995](2003), para quem as práticas lingüísticas 
(...) não são imputáveis a um sujeito cognitivo abstrato, racional, intencional e ideal, solitário face ao mundo, mas a uma construção de objetos cognitivos e discursivos na intersubjetividade das negociações, das modificações das ratificações de concepções individuais e públicas do mundo (MONDADA e DUBOIS, [1995](2003), p. 17).

Nesta perspectiva, a referência é um processo de negociação realizado pelos falantes no momento da interação, à medida que o discurso se desenvolve. Aqui, não interessa saber se a representação do mundo é adequada, nem se trata, simplesmente, da questão da interpretação pelo contexto; interessa, antes, discutir a maneira como se dão as atividades cognitivas e interativas que os falantes praticam ao se referirem ao mundo através da sua fala.

Em nosso trabalho, não fazemos distinção terminológica entre referência e referenciação, usando ora um, ora outro termo. Contudo, Mondada e Dubois [1995] (2003) preferem o termo referenciação, que acrescenta a noção de que se trata de um processo, trazendo também a vantagem de enfatizar a oposição ao conceito clássico de referência, cuja preocupação básica é a de fazer corresponderem as palavras às coisas. Mas, como se sabe, o sentido das coisas não está completamente pré-definido. $\mathrm{O}$ que acontece é que os objetos do mundo, ao serem referidos pelo falante, passam pelo filtro de percepção desse indivíduo, que, como cada um dos outros falantes da língua, tem uma experiência particular de vida e carrega sua própria bagagem de conhecimento, moldada pelas imposições culturais e ideológicas de sua sociedade e de sua época. Essas marcas influenciam na construção da referência.

Se, de um lado, não há uma estabilidade a priori no mundo, por outro, a língua também não é um inventário imutável de palavras prontas para serem usadas. Como bem observou Marcuschi (2004, p. 268), “a linguagem não tem uma semântica imanente, mas ela é um sistema de símbolos indeterminados em vários níveis (sintático, semântico, morfológico e pragmático)". Durante a interação, as categorias discursivas e cognitivas evoluem e se modificam; as escolhas lexicais são adaptadas e reconstruídas de acordo com o que está sendo negociado e com as intenções dos interlocutores. Assim, nesse campo movediço que é a referenciação, os efeitos de objetividade e realidade que criam a ilusão de estabilidade não são dados, mas são frutos dos processos de negociação entre os falantes e podem ser modificados a cada nova interação.

Nesse sentido, então, propomos, desde Ciulla (2008) uma abordagem que leve em conta vários fatores da dimensão discursiva, isto é, a fusão que emerge da ação dos falantes entre si e sobre os objetos do mundo, levando-se em consideração os aspectos culturais e de bagagem enciclopédica, além da memória, localização no tempo e no espaço, intenção desses falantes, suas escolhas linguísticas e as negociações de sentido que por eles são realizadas. Dessa dimensão discursiva, torna-se dependente uma visão abrangente do processo referencial e, portanto, também uma interpretação mais completa do fenômeno da categorização.

Ressaltamos, ainda, que, nessa dimensão discursiva, as conexões linguísticas aparentemente superficiais, como os mecanismos coesivos referenciais (conforme KOCH, 1989), dependem também - e essencialmente - de fatores não apenas pragmáticos, mas cognitivos e interacionais. Ou seja, texto e discurso não são vistos como linhas em paralelo, mas como linhas entrecruzadas. 


\section{CATEGORIZAÇÃO E COGNIÇÃO}

De acordo com Bruner (1974), perceber é categorizar, conceitualizar é categorizar, aprender é formar categorias, tomar decisões é categorizar. Como essas atividades também estão diretamente envolvidas no processo de referência, referir também implica categorizar.

Bruner (1974), no entanto, parte do princípio de que as informações de entrada, ou seja, as informações sobre o que percebemos no mundo, são organizadas em termos de categorias pré-existentes - o que contraria frontalmente nossa abordagem neste trabalho. A categorização é, na verdade, um processo que evidencia ainda mais o caráter de construção discursiva da referência, como demonstraremos no decorrer deste trabalho.

Para Lakoff (1987), a organização do mundo através da razão e do pensamento tem uma base física, material, corporal; o autor afirma que nossas experiências materiais e a maneira como usamos a imaginação são centrais na forma de construir categorias e dar sentido às experiências. Para ele, o pensamento é encarnado, imaginativo, tem propriedades gestálticas e uma estrutura ecológica. A razão, diz Lakoff (1987), só é possível através do corpo - e, nesse sentido, aproxima-se do enacionismo. E, ainda, sob o ponto de vista do autor: sem a capacidade de categorizar, não podemos funcionar quer no mundo físico, quer no mundo social ou intelectual; a compreensão de como categorizamos é central para a compreensão de como pensamos, de como funcionamos e do que nos faz seres humanos.

Reforçando a opinião de que as categorias não são arbitrárias, como pensavam os psicólogos behavioristas, Rosch (1978) apresenta sua Teoria Prototípica. A autora cita o seguinte trecho de Jorge Luis Borges, que trata de uma taxonomia do reino animal, atribuída a uma enciclopédia chinesa:

\footnotetext{
Nestas páginas remotas está escrito que os animais são divididos (a) nos que pertencem ao Imperador, (b) nos embalsamados, (c) nos que são treinados, (d) nos porcos lactantes, (e) nas sereias, (f) nos fabulosos, (g) nos cães de rua, (h) naqueles que estão incluídos nesta classificação, (i) nos que tremem como se fossem loucos, (j) em enumeráveis, (k) naqueles desenhados com um fino pincel de camelo, (l) em outros, (m) naqueles que acabaram de quebrar um vaso de flores, (n) naqueles que parecem moscas à distância. (Jorge Luis Borges, 1966 - citado por ROSCH, 1978, p.27)
}

Rosch (1978) observa que alguns sistemas de classificação podem aparecer na imaginação dos poetas, sem necessariamente corresponder a classes de objetos que existem na prática ou que tenham sido organizados pelo homem em algum contexto cultural. Para Rosch (1978), a categorização acima é possível porque a categorização humana não deve ser considerada como um produto arbitrário de um acidente histórico ou do capricho do ser humano, mas como o resultado de princípios psicológicos de categorização.

Para cada conceito, segundo a autora, existem representantes mais ou menos típicos, sendo que alguns membros podem representar melhor uma categoria do que outros, pois nem todos os membros possuem o mesmo status. Por isso, podemos 
dizer que nem todos os elementos pertencentes a uma categoria compartilham exatamente as mesmas características, sendo que estas podem ou não ser mais comuns ou mais facilmente associadas aos membros de uma categoria em geral. Assim sendo, os melhores exemplos de elementos de uma classe, definidos como aqueles que contêm aspectos que melhor refletem a estrutura da categoria como um todo, são chamados de protótipos ou elementos prototípicos. Então, em uma categoria existem elementos prototípicos, isto é, exemplares mais representativos e distintivos, os quais são mais facilmente reconhecidos, uma vez que possuem mais características compartilhadas por outros membros da mesma categoria, e menos características de membros de outras categorias; e elementos periféricos, isto é, membros de uma categoria que compartilham poucas características com os outros elementos de sua categoria.

Nesta teoria, Rosch (1978) propõe o conceito de hierarquias conceituais, utilizadas na representação das inclusões de classe entre as categorias. A hierarquia se compõe de três níveis: o nível superordenado, o nível básico e o subordinado. Como exemplo dessa hierarquia podemos citar animal, como categoria do nível superordenado, cão, para o nível básico e labrador, para o nível subordinado. Estes conceitos implicam não uma visão de exatidão acerca dos elementos, mas sim uma interpretação em termos de graus de prototipicidade. Para a autora, embora a lógica trate as categorias como possuindo membros que ou pertencem completamente ou não pertencem de todo a uma categoria, as línguas naturais possuem, elas mesmas, mecanismos lingüísticos para a codificação e tratamento de gradientes entre os membros de uma categoria.

Ao postular a flexibilidade entre as categorias, visto que os protótipos não são considerados como fronteiras estanques entre um e outro representante da categoria em que se enquadram, Rosch introduz a lógica fuzzy na Psicologia e na Teoria da Cognição.

Um outro conceito interessante em Rosch (1978) é o da estereotipia, compreendida como um fenômeno de economia cognitiva, segundo o qual as representações de conhecimento no sujeito se organizam, permitindo que uma grande quantidade de informação possa ser processada com o mínimo de esforço cognitivo. Conforme a autora, há processos evolutivos que resultam na transformação de protótipos em estereótipos. Os nomes que denotam categorias ditas básicas (como cão e gato) são responsáveis pela estabilização dos protótipos em diferentes processos comunicativos, pois conceitualizam uma entidade em um nível de representação intermediário, nem superordenado (categorias expressas por hiperônimos, como animal), nem subordinado (hipônimos, como labrador e persa). Já em um segundo momento, através da comunicação lingüística, de acordo com a autora, o protótipo poderia ser compartilhado entre uma grande quantidade de indivíduos, por meio da sua nomeação, o que o tornaria um objeto socialmente distribuído e estabilizado num determinado grupo de sujeitos. O protótipo compartilhado evoluiria para uma representação coletiva, então, que a autora chama de estereótipo.

Porém, sob o ponto de vista que defendemos neste trabalho, acreditamos que tanto na prototipia quanto na estereotipia o processo é coletivo, no sentido de 
que nos dois processos está envolvida a negociação entre os falantes que permite uma certa estabilização (sujeita constantemente a renegociações) dos significados. Isso porque um protótipo não é construído exatamente por ter características inerentes ou naturais, mas também é fruto da ação dos falantes que, em conjunto, em determinado contexto histórico, social e cultural, percebem e estabilizam um certo significado. Isso explica, por exemplo, por que categorizamos tomate como legume e não como fruta: a questão é que utilizamos esse vegetal mais freqüentemente como salada, pelo menos no Brasil, nos tempos atuais, ainda que, sob o aspecto estritamente biológico, tomate compartilhe das características do grupo das frutas.

O que nos parece mais saliente na diferença entre a prototipia e a estereotipia não é o processo em si, mas a motivação, pois, freqüentemente, o estereótipo manifesta um preconceito social e/ou uma qualidade pejorativa. Um exemplo de como a estereotipia pode estar envolvida na categorização em alguns textos é a seguinte:

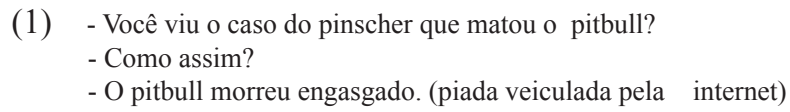

Neste exemplo, a relação não é entre as hierarquias de classes superordenada/ nível básico, mas entre subordinada/subordinada, cujas características estereotípicas estão em jogo. O pitbull identifica-se em alto grau dentro de uma categoria que poderíamos chamar de "cães perigosos", enquanto que o pinscher enquadra-se como pertencendo, em alto grau, a uma classe de "cães inofensivos", principalmente em um confronto entre as duas raças. A aposta da piada está justamente na categorização do pitbull como o estereótipo do "cão perigoso" e do pinscher como o estereótipo do "cão inofensivo". Inicialmente, o interlocutor se surpreende, pois sua expectativa é quebrada; depois, o esquema de agressividade de cães que ele tinha em mente é confirmado e, embora a graça da piada esteja no modo como o pitbull morre, ainda assim, o ponto explorado é a inversão de características entre as raças de cães, isto é, o modo como, de um modo geral, categorizamos pinschers e pitbulls, com base em estereótipos.

A teoria de Rosch (1978), apesar de haver representado um progresso na compreensão de alguns fenômenos da categorização, deixa sem respostas, de acordo com Cuenca e Hilferty (1999), questões importantes, tais como a possibilidade de haver mais de um protótipo em cada categoria e a quantidade de características em comum com outros membros de uma categoria que um protótipo deve ter - se é que seria possível quantificá-las. Além disso, de acordo com Hampton (1981), parece que a noção de protótipo não se aplica tão bem a conceitos mais abstratos, como dor e felicidade, nem a processos mentais, como comparação e inferência e nem mesmo a certas entidades concretas, como as formas geométricas. Outro ponto importante que ressaltamos é que o modelo de protótipo é limitado pelo conhecimento que o indivíduo tem sobre as relações entre as categorias. 
Em resposta a essas limitações relativas à teoria dos protótipos, podemos mencionar, por exemplo, o conceito de semelhança de família, conforme Wittgenstein [1953](1975). Em suas Investigações filosóficas, Wittgenstein defende a idéia de que o significado de uma palavra não é um objeto específico que lhe corresponde, mas o aglomerado de usos afins (familiaridades) que ela tem na linguagem. E afasta a idéia de que os elementos tenham algo em comum, pois, para ele, isso remete à noção de representações mentais fixas, em que um traço sobre determinada coisa é registrado e os falantes nada mais fariam do que comparar o objeto em questão com aquele registro interno. Um dos exemplos citados pelo autor é o da comparação entre os jogos: assim como podemos encontrar semelhanças, podemos encontrar muitas diferenças entre os jogos de tabuleiro; estes têm semelhanças - mas também diferenças - em relação aos jogos de carta. E esses jogos, se comparados aos jogos de bola, muitas coisas em comum se conservam, mas muitas se perdem. Podemos estabelecer uma comparação entre jogos de esforço mental, paciência e os de esforço físico e assim por diante. E o resultado dessa consideração, diz Wittgenstein [1953](1999), é uma rede complexa de semelhanças, que se envolvem e se cruzam mutuamente:

\footnotetext{
Não posso caracterizar melhor essas semelhanças do que com a expressão "semelhanças de família"; pois assim se envolvem e se cruzam as diferentes semelhanças que existem entre os membros de uma família: estatura, traços fisionômicos, cor dos olhos, o andar, o temperamento, etc., etc. - E digo: os “jogos” formam uma família. (WITTGENSTEIN, [1953] (1999), p.52, § 67)
}

Numa família, dois irmãos podem se parecer e apenas um deles se parecer com a mãe, por exemplo; isso é possível porque as características que fazem um dos irmãos se parecer com a mãe não são as mesmas que ele compartilha com o irmão; assim, nos jogos (e em outras categorias), dependendo do tipo de aspecto que escolhemos ressaltar, podemos fazer múltiplas associações.

Por isso, se aliarmos a noção de semelhança de família à teoria dos protótipos, poderemos dizer, então, que as relações entre os membros de uma categoria nem sempre se dão, para os falantes, entre os objetos em questão e o protótipo. Pode ocorrer que um elemento seja integrado a uma categoria porque, para os falantes, compartilha uma semelhança com algum elemento dessa categoria que não é necessariamente o protótipo. Portanto, nem todos os membros de uma categoria precisam ter algum atributo comum entre si e nem mesmo algum atributo em comum com o protótipo, pois as possibilidades associativas são múltiplas.

Também a partir da noção de semelhança de família e considerando que são os falantes, em sua atividade interativa e social, os responsáveis pelas categorizações, afastamo-nos da idéia de protótipo-objeto (elemento concreto que seja prototípico) e aproximamo-nos de uma noção de protótipo-entidade cognitiva, isto é, uma construção resultante de operações cognitivas, que produziria um efeito de prototipicidade, devido ao caráter instável, múltiplo e flexível das categorias construídas pelos seres humanos. 
Assim, quando falamos em categorias estabilizadas por protótipos, é preciso lembrar, pelo menos, de duas questões centrais: uma é a multiplicidade e a imprevisibilidade de combinações que podem compor uma categoria, bem como sua possível mutação; a outra é que as operações cognitivas, como a prototipia, não podem ser vistas de maneira independente da ação coletiva dos falantes.

\section{CATEGORIZAÇÃO E PROCESSOS REFERENCIAIS}

Alguns autores fazem distinção entre categorizar e recategorizar, como Apothéloz e Reichler-Béguelin (1995) e Koch e Marcuschi (1998). Optamos, em Ciulla (2002), por considerá-los também como processos distintos, tendo em conta que, enquanto na categorização um elemento seria introduzido no discurso, na recategorização um elemento já referido seria reformulado, sendo o seu significado alterado de algum modo. Considerávamos uma diferença entre os dois processos, portanto, no que tange à remissão: na recategorização um elemento seria retomado e na categorização não haveria retomada. Contudo, essa distinção pode se revelar problemática. Atentemos para o exemplo, a partir da leitura de um conto de Moreira Campos:

(2) O ferro em brasa, que a própria mulher do filho trouxe da trempe de tijolos na cozinha. O gemido, contorções do corpo. A pele de fumo voltou a cobrir a ferida. Morreu três horas depois. Longe os vizinhos. Légua e meia o mais próximo. Belarmino teve de ir até lá (o cachorro enrolava-se no chão sob a tipóia do morto). Trouxe outros seres em molambos e grunhidos. E a marcha fúnebre - tipóia oscilante presa à estaca de sabiá - se fez em direção ao distante arruado, onde havia a capela e o telheiro abatido do mercado. No mais, a solidão da noite e dos seres. A viúva-menina, sem lágrimas. Duro mundo, carente de umidades. Muitas lições de renúncia. Tão trabalhados todos como a escarpa fendida e crestada pelo tempo, por onde subiam bodes e cabras. (Moreira Campos, O peregrino)

Quando, pela primeira vez, há uma referência à personagem feminina, ela aparece como "mulher do filho", e seria o caso de uma categorização, pela introdução de um elemento ainda não mencionado no texto. Quando é retomada, a mesma personagem é referida como "viúva-menina", o que lhe acrescenta a informação de ser muito jovem, pela escolha de "menina", e enfatiza sua condição de mulher sem marido, pela escolha da expressão "viúva". A expressão "mulher do filho" seria, portanto, recategorizada como "viúva-menina". Além disso, a expressão "viúva-menina" é uma expressão anafórica, pois retoma "mulher do filho", que, por sua vez, de acordo com a classificação por nós adotada em Ciulla (2002), seria uma introdução referencial, por não haver nenhuma menção anterior ao referente ao qual remete essa expressão. Num primeiro momento, as relações de categorização, no exemplo (2), poderiam assim ser explicadas. Porém, a observação mais minuciosa nos fez perceber um problema em distinguir entre categorização e recategorização.

Observando novamente a expressão "a própria mulher do filho", embora se trate de uma introdução referencial, não é possível afirmar que, para construir 
esse referente, ele não tenha sofrido um reajuste, um remodelamento, isto é, uma recategorização. Isso porque não existe um modelo a priori de "a própria mulher do filho", mas apenas algumas pistas lexicais e a aposta de que, com base em sua experiência e conhecimento particulares, o leitor poderá recriar este personagem. $\mathrm{E}$, nesse processo de recriação, os conceitos são reacomodados, pois há muitas coisas que variam a cada interação, devido aos vários fatores da dimensão discursiva, conforme mencionamos anteriormente.

Podemos dizer, então, que a recategorização depende do conhecimento prévio do interlocutor e pode ser instalada independentemente de menção no texto. De acordo com Cavalcante (2011), a recategorização é, por definição, uma alteração nas associações entre representações categoriais parcialmente previsíveis, portanto, em nossa visão pública de mundo. Isso significa que a remissão não é uma condição obrigatória para a recategorização, que pode ocorrer independentemente dela, conforme exemplificamos em (2). Portanto, considerando que pode haver recategorização, seja através de uma expressão de introdução referencial, seja através de uma expressão de continuidade referencial, a associação obrigatória que vínhamos fazendo desde Ciulla (2002) entre categorização/introdução referencial em oposição a recategorização/anáfora não é mais válida.

Um ponto importante a ser notado é que a recategorização não é um fenômeno que se restringe a um ou outro processo referencial. A questão é que categorizar implica sempre numa nova categorização, se pensamos do ponto de vista de que a referência é um processo em constante mutação. Em outras palavras, categorizar é sempre recategorizar, o que torna redundante e esvazia, em parte, o sentido desse último termo ${ }^{1}$. Tal afirmação pode ser sustentada com base em abordagens como a de Johnson (1987), que defende a noção de que os seres humanos possuem estruturas cognitivas muito gerais, que têm origem em nossas experiências corpóreas. Através de um estudo detalhado com vários exemplos, o autor explica sua hipótese de que formamos esquemas que emergem de nossas experiências sensório-motoras. Tais esquemas seriam projetados através do poder imaginativo dos seres humanos, não sendo considerados arbitrários, mas alcançados por procedimentos metafóricos e metonímicos que, acrescentamos aqui, também não são apenas processados e reprocessados internamente, mas são renegociados coletivamente pelos falantes. Isso explica, por exemplo, mudanças de significados de palavras relacionadas a esquemas mais básicos e concretos para significados mais abstratos, como o do verbo "ver" que pode ser estendido para "entender".

Também Lakoff (1988) afirma que as estruturas conceituais que compõem o significado (e, portanto, estão também na base do processo de categorização) têm origem em duas fontes: a natureza estruturada da experiência corpórea e social e a nossa capacidade inata de projetar de maneira imaginativa alguns aspectos da nossa corporificação e interação e formar estruturas abstratas. Para este autor, "o pensamento racional é a aplicação de processos cognitivos muito gerais focalização, scanning, superimposição, reversão de figura-fundo, etc. - a essas estruturas" (LAKOFF, 1988, p.89).

${ }^{1}$ Há situações, contudo, em que queremos enfatizar as categorizações sucessivas em um texto ou trecho de texto, casos em que empregaremos, eventualmente, a expressão recategorização. 
Com base em estudos como os que citamos, de Johnson (1987) e Lakoff (1988), defendemos a hipótese de que, sendo as estruturas conceituais que guardamos das coisas tão gerais e sujeitas a modificações, mesmo quando nos deparamos pela primeira vez com um objeto, é preciso um procedimento de formulação para categorizá-lo. Do mesmo modo, aliás, acontece com uma recategorização anafórica, isto é, associamos características dos objetos que percebemos no mundo ao conhecimento de que dispomos, seja ele fornecido pela situação mais imediata (no caso das anáforas, por um elemento referido no próprio texto), seja pela nossa memória e pela experiência de outras percepções e interações, ou melhor, pelo conjunto de tudo isso. Em suma, se dissemos que recategorizar é alterar categorias parcialmente previsíveis, e as categorias são sempre mais ou menos previsíveis, então podemos dizer que categorizar implica sempre numa recategorização.

As interpretações a respeito dos processos de categorização, a exemplo do que fizemos acima, a partir do exemplo (2), confirmam as noções de instabilidade dos objetos e do mundo e de objetos evolutivos de Apothéloz e Reichler-Béguelin (1995), já que os objetos podem ser redefinidos a cada nova interação entre os falantes. Por isso, estão em jogo, também no processo de categorização, aspectos cognitivos, como a experiência pessoal, a capacidade de inferência, a bagagem de conhecimento linguístico e enciclopédico do indivíduo.

A partir das observações que fizemos, confirmamos também que a categorização é um fenômeno intimamente ligado à referenciação: todo ato de referir implica, também, categorizar, pois ao escolher uma expressão, entre todas as opções que julgar adequadas, incluindo-se aí as invenções, adaptações e transformações, o falante privilegia alguns aspectos e algumas semelhanças de família em detrimento de outros, de acordo com as discriminações (ou abstrações ou generalizações, etc.) que a palavra escolhida pode comportar naquela situação de uso. Frisamos que essa seleção não é limitada por um número definido de opções, já que o falante pode até mesmo criar expressões e inventar categorias de acordo com seus propósitos. Estão em jogo, nessa seleção, a habilidade, a memória e o conhecimento do falante e de seu interlocutor e também os recursos da própria língua.

Os exemplos apontam também para o fato de que o fenômeno da categorização não pode ficar restrito às operações meramente lexicais, pois, muitas vezes, apóia-se muito mais na capacidade de inferência do interlocutor, no seu conhecimento de mundo e no conhecimento compartilhado entre os falantes. Isso instiga muitas questões, como as de quais implicações têm os diferentes tipos de categorização para o discurso.

Jaguaribe (2005), em uma análise de um poema de Manuel Bandeira, demonstra como a categorização de uma introdução referencial - e que também não remete, a princípio, a nenhuma outra obra em especial - pode ser realizada através de várias reformulações. Com o auxílio deste exemplo, mostramos também como as categorizações dependem simultaneamente do léxico e das operações cognitivas, num processo indissociável: 
(3) A DAMA BRANCA

A Dama Branca que eu encontrei,

Faz tantos anos,

Na minha vida sem lei nem rei,

Sorriu-me em todos os desenganos.

Era sorriso de compaixão?

Era sorriso de zombaria?

Não era mofa nem dó. Senão,

Só nas tristezas me sorriria.

E a Dama Branca sorriu também

A cada júbilo interior.

Sorria como querendo bem.

E todavia não era amor.

Era desejo? - Credo! De tísicos?

Por histeria... quem sabe lá?...

A Dama tinha caprichos físicos:

Era uma estranha vulgívaga.

Ela era o gênio da corrupção.

Tábua de vícios adulterinos.

Tivera amantes: uma porção.

Até mulheres. Até meninos.

Ao pobre amante que lhe queria, Se lhe furtava sarcástica.

Com uns perjura, com outros fria, Com outros má.

- A Dama Branca que eu encontrei, Há tantos anos,

$\mathrm{Na}$ minha vida sem lei nem rei,

Sorriu-me em todos os desenganos.

Essa constância de anos a fio, Sutil, captara-me. E imaginai! Por uma noite de muito frio

A Dama Branca levou meu pai.

(Manuel Bandeira, A dama branca - citado por JAGUARIBE, 2007, p.11-2)

A princípio, lendo-se somente a expressão "dama branca" podemos interpretá-la - e provavelmente a maior parte dos leitores o faria - como uma mulher, especialmente num poema, em que mulher é um tema freqüente. No entanto, no último verso, mais especialmente por causa da expressão "levou meu pai", percebemos que a "dama branca" é a morte. No entanto, essa passagem, de uma a outra, faz com que a construção do objeto morte seja feita sob um determinado ponto de vista, enfatizando certos sentimentos de dor e tortura que o autor do poema quis atribuir à morte. Sobre a expressão "A dama branca", do título, Jaguaribe (2005) salienta que: 
(...) essa introdução referencial já se faz por meio de uma recategorização. Tendo em vista que o processo de categorização tem um forte componente cultural, não nos parece coerente desconsiderar que o objeto-do-mundo "morte" já se encontra devidamente categorizado em nossa sociedade; o que fez o poeta foi enfocá-lo em uma nova perspectiva, como convém à palavra poética. (JAGUARIBE, 2005, p.12)

Outros aspectos sobre os processos referenciais desse poema podem ser explorados, como, por exemplo, os recursos utilizados - em especial as categorizações - para que o leitor possa construir a imagem da morte como o de uma prostituta ("Era uma estranha vulgívaga./Ela era o gênio da corrupção./Tábua de vícios adulterinos./Tivera amantes: uma porção./Até mulheres. Até meninos.") que finge amar ("Sorria como querendo bem./E todavia não era amor."), causando a dor que uma mulher assim poderia provocar em um homem que dela se enamorasse ("Ao pobre amante que lhe queria,/Se lhe furtava sarcástica./Com uns perjura, com outros fria,/Com outros má.”).

A própria escolha do título, numa referência óbvia a uma figura feminina, já se presta a que, na construção do referente, essa associação entre mulher e morte seja feita - e é aqui que se evidencia, também, que as relações entre léxico e cognição são imbricadas. Na verdade, a explicação para essa relação é a de que a definição das palavras, tal qual ela aparece no dicionário, por exemplo, é apenas parte daquilo que um falante utiliza para atribuir-lhe um significado. Sem a participação dos falantes e suas atividades cognitivas, o léxico é apenas uma lista de palavras desconectadas.

\section{CONSIDERAÇÕES FINAIS}

Sugerimos, então, que a categorização é um processo cognitivo que se relaciona de maneira estreita com o processo de referência, pois é através dele que decidimos e formulamos as categorias para as quais apontam nossas designações. Nesse processo cognitivo e discursivo, portanto, as categorias não são estanques e mesmo a prototipia é fruto de negociações coletivas, sujeita a constantes modificações. Imprevisíveis e mutantes, as categorias podem, no entanto, ter papéis muito definidos, cuja verificação é possível, considerandose o seu processo de construção no discurso. A questão central, a nosso ver, é que as categorizações e os processos referenciais que são promovidas na malha discursiva imbricam-se, de modo que não podemos interpretar completamente um sem ver o outro. Além disso, a observação de que a categorização não é um fenômeno essencialmente lexical e nem puramente cognitivo reforça a hipótese de que os fenômenos referenciais dependem de uma interpretação em que texto e discurso estão indissocialvelmente imbricados e em que todos os fatores da dimensão discursiva são levados em conta.

\section{REFERÊNCIAS BIBLIOGRÁFICAS}

APOTHÉLOZ, D.; REICHLER-BÉGUELIN, M-J. Interpretations and functions of demonstrative NPs in indirect anaphora. Journal of Pragmatics, v. 31, n. 3, p. 363-397, mar. 1999. 
CIULLA - Categorização e referência: uma abordagem discursiva.

BRUNER, J. Going beyond the information given. New York: Norton. 1974.

CAVALCANTE, M.M. Referenciação: sobre coisas ditas e não ditas. Fortaleza: Edições UFC, 2011. V. 1. $192 \mathrm{p}$.

CAVALCANTE, M.M. Expressões indiciais em contextos de uso: por uma caracterização dos dêiticos discursivos. 2000. 204 f. Tese de Doutorado em Lingüística - Universidade Federal de Pernambuco, Recife.

CIULLA, A. Os processos de referência e suas funções discursivas: o universo literário dos contos. 201p. Tese (Doutorado em Linguística). Universidade Federal do Ceará, Fortaleza, 2008.

CIULLA, A. A referenciação anafórica e dêitica - com atenção especial para os dêiticos discursivos. 2002. 90 p. Dissertação de Mestrado em Lingüística - Universidade Federal do Ceará, Fortaleza.

CUENCA, M.J. e HILFERTY, J. Introducción a la lingüística cognitiva. Barcelona: Editorial Ariel, 1999.

HAMPTON, J. An investigation of the nature of abstract concepts. Memory \& cognition, 9, 1981, p.149-56.

JAGUARIBE, V. M. F. A recategorização no texto literário - as negociações discursivas em poemas. 2005. 75 p. Projeto de Tese de Doutorado - Universidade Federal do Ceará, Fortaleza.

JOHNSON, M. The body in the mind: the bodily basis of meaning, imagination and reason. University Chicago Press, 1987.

KOCH, I. A coerência textual. Editora Contexto: São Paulo, 1989.

KOCH, I.; MARCUSCHI, L.A. Processos de referenciação na produção discursiva. Revista DELTA, $14, \mathrm{n}^{\circ}$ especial, 1988.

LAKOFF, G. Women, Fire, and Dangerous Things. University of Chicago Press, Chicago, 1987.

MARCUSCHI, L. A. O léxico: lista, rede ou cognição social? In: FOLTRAN, M. J (org.). Sentido e significação - em torno da obra de Rodolfo Ilari. São Paulo: Contexto, 2004, p. 263-84.

MONDADA, L.; DUBOIS, D. Construction des objets de discours et catégorisation: une approche des processus de référenciation. In: TRANEL (Travaux Neuchâtelois de Linquistique), n.23, 1995, p.273-302. Tradução para o português : Construção dos objetos do discurso e categorização: uma abordagem dos processos de referenciação. In: CAVALCANTE, M. M.; RODRIGUES, B. B.; CIULlA, A. (orgs.) Referenciação. São Paulo: Contexto, 2003, p. 17-52.

ROSCH, E. Principles of categorization. In: .; LLOYD, B.B. (eds) Cognition and Categorization. New Jersey: Lawrence Erlbaum, 1978.

WITTGENSTEIN, L. Recherches philosophiques. Tradução francesa de Jacques Fauve. Paris: editions Gallimard, 1975. 